\title{
Optimal Fiscal and Monetary Policies Under Limited Asset Market Participation
}

\author{
Lorenzo Menna ${ }^{1}$ (D)
}

Received: 4 March 2016 / Accepted: 15 July 2016 / Published online: 28 July 2016

(C) Società Italiana degli Economisti (Italian Economic Association) 2016

\begin{abstract}
I reconsider the issue of optimal monetary and fiscal policy in a fully fledged DSGE model augmented for a share of agents excluded from asset market participation (rule-of-thumb consumers) when many fiscal instruments are available. Limited asset market participation entails a stronger use of the consumption tax in place of the labor tax in steady state. Along the business cycle, monetary policy stabilizes inflation while fiscal policy can play an important role in attenuating the effect of productivity shocks on income distribution.
\end{abstract}

Keywords Trend inflation · Monetary and fiscal policy · Ramsey plan · Limited Asset Market Participation

JEL Classification E63 $\cdot$ E58 $\cdot$ E32

\section{Introduction}

The standard normative result in New Keynesian models characterized by price stickiness is that monetary policy can replicate the flexible price allocation by completely stabilizing inflation (Blanchard and Galì 2007), which renders the role of fiscal policy of secondary importance. Under medium scale DSGE models with nominal and real rigidities, monetary policy remains the main tool for business cycle stabilization;

The opinions expressed here are those of the author and do not necessarily represent Banco de Mexico's or its board of governors' opinions.

Lorenzo Menna

lorenzo.menna@banxico.org.mx; lorenzomenna@yahoo.it

1 Direccion General de Estabilidad Financiera, Direccion de Analisis de Riesgos Macrofinancieros Banco de Mexico, Av. 5 de Mayo 1-1er Piso Col. Centro, Mexico City 06059, Mexico 
while optimal fiscal policy is passive (Schmitt-Grohe and Uribe 2007). Standard New Keynesian DSGE models rest on the representative agent assumption which is only valid as long as everybody participates to financial markets and marginal rates of substitution are equalized among agents. Such assumptions are at odds with the data, as shown by a growing body of literature (see, for instance, Vissing-Jørgensen 2002). A convenient device to introduce heterogeneity in a standard DSGE model has been used in a second strand of New Keynesian literature which, following a seminal contribution by Mankiw (2000), emphasizes the role of rule-of-thumb (RT henceforth) consumers who do not participate to financial markets and therefore cannot save or borrow. Galì et al. (2004) as well as Furlanetto and Seneca (2009) show that this form of limited asset market participation (LAMP henceforth) can rationalize the empirically observed response of aggregate consumption to public spending shocks. In Furlanetto and Seneca (2012), the LAMP hypothesis helps account for recent empirical evidence on productivity shocks.

The evidence for limited participation to asset markets is overwhelming. As Table 1 shows, in the United States only a small minority of households participate in the stock (15.1\%) and bond market (1.6\% for common bonds and $12 \%$ for savings bonds). Other types of assets are all held by less than the $50 \%$ of households, apart from retirement accounts $(50.4 \%)$ and transaction accounts $(92.5 \%)$, the latter being a form of non-interest bearing money. ${ }^{1}$ Other evidence suggests that a small minority of households holds the greatest part of wealth in several countries. Alvaredo et al. (2013), for instance, show that the top $1 \%$ of wealth holders owns $35 \%$ of total wealth in the US and 20-25\% in Europe. The great majority of the population has either little wealth (usually in the form of housing) or no wealth at all. The fact that a substantial share of the population in several countries holds very small amounts of liquid wealth has two classes of consequences that are of interest for policy-makers. First, many households do not receive any income in the form of profits, dividends, rents and interests. Inequality in capital income can in principle be important from an optimal taxation perspective. Second, such households may have difficulties smoothing consumption over time. In fact, poor households are also often borrowing-constrained. Between 40 and $60 \%$ of respondents to the Survey of Household Economics and Decisionmaking (2014) conducted by the FED in 2013 said that they would be unable to cover three months of their expenditures by either using their savings or by borrowing. ${ }^{2}$ This fact has important implications for counter-cyclical fiscal policy, as it invalidates the Ricardian equivalence principle, and opens up the possibility of using government policies to help households insure against idyosincratic shocks. There are several explanations for LAMP, ranging from fixed asset market participation costs and agency costs (Bo Sun 2011) to rational inattention (Rachedi 2016).

Introducing RT consumers in an otherwise standard DSGE model allows to study these issues in a relatively simple framework. The present paper considers a fully fledged DSGE model with capital, nominal rigidities, real rigidities and RT consumers,

\footnotetext{
1 Transaction accounts are part of M1.

2 In particular, $57.9 \%$ responded no to the question "Have you set aside emergency or rainy day funds that would cover your expenses for 3 months?". $42.2 \%$ responded no to the question "Could you cover your expenses for 3 months by borrowing money, using savings, selling assets, or borrowing from friends/faily?".
} 
Table 1 Data taken from the Federal Reserve Bullettin, June 2012, Vol 98, No 2. 2010 Survey

\begin{tabular}{lc}
\hline & Percentage of families holding asset \\
\hline Transaction accounts & 92.5 \\
Certificate of deposits & 12.2 \\
Savings bonds & 12.0 \\
Bonds & 1.6 \\
Stocks & 15.1 \\
Pooled investment funds & 8.7 \\
Retirement accounts & 50.4 \\
Cash value life insurance & 19.7 \\
Other managed assets & 5.7 \\
Other & 8.0 \\
Any financial asset & 94.0 \\
\hline
\end{tabular}

in which the planner has access to both monetary and fiscal instruments; and uses it to assess how such instruments should be used when redistributive issues are important. In practice, the Ramsey planner chooses the optimal inflation rate and the optimal capital, consumption and labor tax rate, with the objective of maximizing a social welfare function, given by a weighted sum of asset market participants (ricardian agents, henceforth) and RT consumers utility functions. The share of RT consumers is set to $40 \%$, a rather conservative value, given that participation to the stock and bond market is much lower. However, values close to 0.4 arise in several empirical estimations of the share of RT consumers (see for instance Mankiw 2000; Galì et al. 2004). In particular, I contribute to two strands of literature.

The first strand of literature to which this paper is related studies optimal taxation in the steady state equilibrium, when government spending is exogenously given. Seminal contributions in the standard representative agent neoclassical framework are (Chamley 1981, 1986), Chari et al. (1994) and Coleman (2000), among others. They find that optimal policy requires a zero capital tax in the long run. Coleman (2000), in particular, shows that it is optimal to tax consumption and subsidize labor as long as public expenditures include transfers and the consumption tax base is higher than the labor tax base, which is verified in both the model and the data. SchmittGrohé and Uribe (2006) analyze the optimal tax scheme in a model with monopolistic competition, price stickiness and monetary transaction costs, but without consumption taxes. They find that a capital subsidy becomes optimal, and the latter is higher if it is possible to tax monopolistic profits separately from capital income. One of the few papers that considers a heterogenous agent economy in this strand of literature is Judd (1985), which takes into account a model with workers (who do not hold any wealth) and capitalists and finds that the optimal capital tax remains zero notwithstanding the possibility to use it to redistribute income. Indeed, taxing capital reduces the long run capital level, depresses real wages and ends up reducing workers' income. In this paper I find that the optimality of a zero or even negative capital tax is robust to the introduction of LAMP. However, the framework considered here allows to obtain 
novel results for what concerns the relative importance of labor and consumption taxes. First of all, I find that under the representative agent assumption, the result of Coleman (2000) that consumption taxes are preferable to labor taxes is not robust when firms are subject to fixed production costs. In the presence of such costs, it is indeed the case that the Ramsey planner prefers to set the labor tax rate higher than the consumption tax rate. However, the consumption tax is again preferable to the labor tax once LAMP is introduced in the model. The intuition for this result is that while the labor tax burden disproportionately falls on RT consumers whose sole source of income is labor, consumption taxes allow to indirectly tax profits, which only accrue to Ricardian agents. As the latter own the whole wealth of the economy and earn higher incomes, consumption taxes serve the purpose of redistribution. Differently from the capital income tax, the consumption tax does not distort the consumption-investment decision in the steady state ${ }^{3}$ and is less distortionary.

The second strand of literature to which this paper contributes investigates the optimal monetary and fiscal stabilization policies along the business cycle, which are usually studied in a New Keynesian framework in the presence of nominal rigidities. As already mentioned, the seminal contribution of Schmitt-Grohe and Uribe (2007) finds that the bulk of business cycle stabilization should be implemented through monetary policy and fiscal policy should be passive. In particular, monetary policy should almost completely stabilize inflation along the business cycle and fiscal policy should limit itself to avoid explosive public debt paths. The robustness of this result under LAMP has been debated in the literature. Ascari et al. (2011) consider a model without an explicit role for fiscal policy and find that if both prices and wages are sticky, monetary policy should simply stabilize inflation fluctuations even in the presence of RT consumers. Motta and Tirelli (2012) find that introducing both LAMP and consumption habits makes fiscal activisms optimal. In particular, while monetary policy should respond to inflation fluctuations even more strongly than under the representative agent model, fiscal policy should aim at stabilizing nominal income growth. Such a policy combination is able to reduce fluctuations in income distribution, which in the presence of consumption habits are particularly costly in terms of welfare. However, this literature usually considers stylized models that abstract from capital accumulation. Furthermore, the fiscal instruments at the disposal of the planner are often limited in number. Motta and Tirelli (2012), for instance, assume that the policymaker can access non-distortionary lump-sum taxes. The present paper shows that optimal fiscal policy aims at reducing fluctuations in income distribution even in the absence of consumption habits, once one allows for capital accumulation. In addition, I show how an optimal combination of distortionary taxes can be used to achieve this result.

To understand why the addition of capital accumulation by itself makes fiscal activism important, consider the response of the economy to a productivity shock. Productivity shocks increase overall income, but redistribute it from RT consumers to ricardian agents, making the former relatively worse off. Fluctuations in income distribution along the business cycle are inefficient as the first best allocation requires

3 A constant consumption tax weighs in the same manner on present and future consumption and does not change the private sector intertemporal consumption allocation. 
that all idyosincratic risks are insured away and the marginal utility ratio between agents is kept constant. ${ }^{4}$ Such inefficiency is the composition of two different effects. First of all, price stickiness tends to cause increases in the mark up of prices over marginal costs, which pushes up monopolistic profits and reduces demand for labor and capital. This first effect can be cured with monetary policy: mark-ups can in fact be completely stabilized if inflation is kept constant at zero. On the other hand, the fact that all capital is in the hands of ricardian agents implies that the increase in the return to capital that follows productivity shocks is completely appropriated by them, which tends to augment the ratio between the income of the wealthiest agents and that of the poorest. Such an effect can not be confronted by monetary policy, which, on the contrary, tends to increase it by stimulating demand for capital through price stabilization. Fiscal policy can instead play a role. The planner temporarily borrows funds from ricardian agents to finance a reduction of the labor tax. This allows to sustain the consumption of RT consumers and stabilize the marginal utility ratio.

The welfare gains from such a policy critically depend on the curvature of the utility function. The more concave the utility function is, the higher are the costs linked to income inequality in the steady state and the higher are the costs of its fluctuations along the business cycle. The optimal policy almost eliminates swings in the distribution of income for a KPR utility function with the curvature parameter set at five. In the log-utility case instead, income distribution is not completely stabilised. Notice, however, that the latter case is probably the less relevant from an empirical point of view. A large literature, beginning with Mehra and Prescott (1985), shows that log-utility, while very common in the macroeconomic literature, is inadequate for fitting asset prices and that much higher curvatures of the utility function must be considered to explain financial data. This suggests that households are much more averse to consumption fluctuations than what is predicted by the log-utility case.

The rest of the paper is organized as follows. In Sect. 2 present the model and the Ramsey problem. Section 3 presents the calibration of the deep parameters of the model. Sections 4 and 5 discuss respectively the optimal deterministic steady state and the optimal Ramsey dynamics. Section 6 concludes.

\section{The Model}

The model I consider is a standard DSGE model augmented with limited asset market participation. It features sticky prices and wages and capital adjustment costs. The government finances an exogenous stream of public consumption by levying labor and capital income taxes along with consumption taxes. Moreover, it sets the nominal interest rate. Monetary and fiscal policies are optimised, in the sense that they are chosen to maximise an utilitarian social welfare function under the constraints given by the competitive equilibrium conditions. Under the utilitarian approach, the social welfare function is given by the weighted sum of the utilities of the two agent types, with weights given by the share of each type over the total population. This approach

\footnotetext{
4 In fact, if markets are complete and all agents have access to them, they completely insure away all idyosincratic risk and consumption fluctuations are exactly the same for all agents.
} 
makes sure that the Ramsey planner cares about inequality, without resorting to more complicated functional forms. In fact, if the utility function of each agent is concave, which is the case if people are risk-averse and averse to consumption fluctuations, then the planner would like to have a consumption inequality which is as smaller as possible.

Furthermore, I assume that the planner has to respect a promise made in an indefinite period in the past. In other words I compute the Ramsey optimal policy under a timeless perspective. As is well known, the Ramsey problem is non-stationary in the sense that the planner's first order conditions at time zero are different from the first order conditions at times $t>0$. The optimization from a timeless perspective amounts to assuming that the initial commitment was made in the past and looks at the asymptotic behaviour of the economy under Ramsey optimal policy. In technical terms this is equivalent to considering the past Lagrange multipliers of the Ramsey program as additional state variables, and setting their value at time -1 to their corresponding steady state value.

\subsection{Households}

There are two types of households. Ricardian households can freely participate to financial markets and save and consume optimally. RT households are constrained to consume their current labor income and cannot optimize. From now on, upper case letters and lower case letters denote nominal and real quantities, respectively. The utility function is of the KPR type:

$$
U\left(c_{t}^{i}, n_{t}^{i}\right)=\frac{1}{1-\sigma}\left(c_{t}^{i}\left(1-\theta n_{t}^{i \phi}\right)\right)^{1-\sigma}
$$

Notice that when $\sigma=1$ the latter expression collapses to a standard log-utility format: $U\left(c_{t}^{i}, n_{t}^{i}\right)=\ln c_{t}^{i}+\ln \left(1-\theta n_{t}^{i \phi}\right)$. The KPR format allows to increase the risk aversion parameter $\sigma$ above one, without renouncing to the good empirical properties of the separable log-utility framework. In fact, the KPR utility function is compatible with a balanced growth path for any value of $\sigma$. Furthermore, the dimension of the wealth effect on labor supply is unaffected by $\sigma$, which allows to avoid unrealistic reductions in the labor supply in the face of positive shocks to income.

\subsection{Ricardian Households}

The problem for the representative ricardian household, indexed by $o$, is:

$$
\max E_{0} \sum_{t=0}^{\infty} \beta^{t} U\left(c_{t}^{o}, n_{t}\right)
$$




$$
s t \quad\left(1+\tau_{c, t}\right) c_{t}^{o}+b_{t}^{o} \leq\left(1-\tau_{n, t}\right) w_{t} n_{t}+\frac{b_{t-1}^{o} i_{t-1}}{\pi_{t}}+d_{t}^{o}-\frac{X}{2}\left(\frac{w_{t} \pi_{t}}{w_{t-1}}-1\right)^{2} n_{t}
$$

Ricardian households earn after tax labor income $\left(\left(1-\tau_{n, t}\right) w_{t} n_{t}\right)$ and dividends $d_{t}^{o}$ and receive payments on past investment in government debt $\frac{b_{t-1}^{o} i_{t-1}}{\pi_{t}}$. They buy an amount of the consumption good equal $c_{t}^{o}$ after paying $\tau_{c, t} c_{t}^{o}$ in consumption taxes and government debt $b_{t}^{o}$. Notice that there is a quadratic cost of adjusting nominal wages.

Ricardian households do not invest directly in capital. Investment in capital is carried out at the level of the intermediate firms. Hence dividends contain both extra-profits deriving from monopolistic competition and the normal return on capital. Moreover, the choice of the labor effort is left to labor unions.

The first order conditions of the problem are:

$$
\begin{gathered}
\lambda_{t}^{o}\left(1+\tau_{c, t}\right)=\left(c_{t}^{o}\right)^{-\sigma}\left(\frac{1-\theta n_{t}^{\phi}}{c_{t-1}^{\chi}}\right)^{1-\sigma} \\
\frac{1}{i_{t}}=\beta E_{t}\left(\frac{\lambda_{t+1}^{o}}{\lambda_{t}^{o}} \frac{1}{\pi_{t+1}}\right) \\
\left(1+\tau_{c, t}\right) c_{t}^{o}+\frac{b_{t}}{1-\psi}=\left(1-\tau_{n, t}\right) w_{t} n_{t}+\frac{b_{t-1} i_{t-1}}{(1-\psi) \pi_{t}}+\frac{d_{t}}{1-\psi}-\frac{X}{2}\left(\frac{w_{t} \pi_{t}}{w_{t-1}}-1\right)^{2} n_{t}
\end{gathered}
$$

where $\psi$ is the share of RT consumers in the population and $\pi_{t}$ is consumer price inflation.

\subsubsection{Rule of Thumb Households}

RT households do not optimize and simply consume their after tax labor income each period:

$$
\left(1+\tau_{c, t}\right) c_{t}^{r t}=\left(1-\tau_{n, t}\right) w_{t} n_{t}-\frac{X}{2}\left(\frac{w_{t} \pi_{t}}{w_{t-1}}-1\right)^{2} n_{t}
$$

The subscript RT indicates that the variables concern a representative RT household. For later use, it is useful to derive the marginal utility of consumption for RT households:

$$
\lambda_{t}^{r t}\left(1+\tau_{c, t}\right)=\left(c_{t}^{r t}\right)^{-\sigma}\left(\frac{1-\theta n_{t}^{\phi}}{c_{t-1}^{\chi}}\right)^{1-\sigma}
$$

\subsection{Aggregation Among Households}

Average marginal utility and aggregate consumption respectively are:

$$
\lambda_{t}=\psi \lambda_{t}^{o}+(1-\psi) \lambda_{t}^{r t}
$$




$$
c_{t}=(1-\psi) c_{t}^{o}+\psi c_{t}^{r t}
$$

\subsection{Unions}

The labor market is characterized by a continuum of differentiated labor inputs on the interval $(0,1)$. As standard under the Dixit-Stiglitz model of monopolistic competition, demand for the differentiated labor of type $\mathrm{h}$ is given by $l_{h t}=\left(\frac{w_{h, t}}{w_{t}}\right)^{-v} n_{t}^{d}$, where $n_{t}^{d}$ is total labour demanded by firms and $W_{h, t}$ is the wage for labour type h. Since I assume that each household supplies all kinds of labour, the amount of hours worked by household i is given by $n_{t}^{i}=\int_{0}^{1}\left(\frac{w_{h, t}}{w_{t}}\right)^{-v} d h n_{t}^{d}$. This is the labour time that appears in the utility functions of the agents and that the unions consider when solving their problem. Hence, the labor income appearing in the budget constraint of the two representative households is $w_{t} n_{t}=\int_{0}^{1} w_{h, t}\left(\frac{w_{h, t}}{w_{t}}\right)^{-v} d h n_{t}^{d}$, where $w_{t}=\left(\int_{0}^{1} w_{h, t}^{1-v} d h\right)^{\frac{1}{1-v}}$ is the wage index.

The labor market is monopolistically competitive in the sense that there is only one union for each labor type h. Each union solves the following problem:

$$
\begin{gathered}
\max E_{0} \Sigma_{t=0}^{\infty} \beta^{t}\left(\left((1-\psi) U\left(c_{t}^{o}, n_{t}\left(w_{h, t}\right)\right)+\psi U\left(c_{t}^{r t}, n_{t}\left(w_{h, t}\right)\right)\right)\right. \\
\text { st }\left(1+\tau_{c, t}\right) c_{t}^{o}+\frac{b_{t}}{1-\psi}=\left(1-\tau_{n, t}\right) \int_{0}^{1} w_{h, t}\left(\frac{w_{h, t}}{w_{t}}\right)^{-v} d h n_{t}^{d} \\
+\frac{d_{t}}{1-\psi}-\frac{X}{2}\left(\frac{w_{h, t} \pi_{t}}{w_{h, t-1}}-1\right)^{2} n_{t} \\
\left(1+\tau_{c, t}\right) c_{t}^{r t}=\left(1-\tau_{n, t}\right) \int_{0}^{1} w_{h, t}\left(\frac{w_{h, t}}{w_{t}}\right)^{-v} d h n_{t}^{d}-\frac{X}{2}\left(\frac{w_{h, t} \pi_{t}}{w_{h, t-1}}-1\right)^{2} n_{t}^{d}
\end{gathered}
$$

The first order condition after aggregating among all unions and considering that all fix the same wage, is the following:

$$
\begin{aligned}
- & \frac{\psi U_{n}\left(c_{t}^{o}, n_{t}\right)+(1-\psi) U_{n}\left(c_{t}^{r t}, n_{t}\right)}{\lambda_{t}} \\
= & \frac{v-1}{v}\left(1-\tau_{n, t}\right) w_{t}+\frac{X}{v}\left(\pi_{W, t} \pi_{t}-1\right) \pi_{W, t} \pi_{t} \\
& -\beta E_{t}\left[\frac{\lambda_{t+1}}{\lambda_{t}} \frac{X}{v}\left(\pi_{W, t+1} \pi_{t+1}-1\right) \pi_{W, t+1} \pi_{t+1} \frac{n_{t+1}}{n_{t}}\right]
\end{aligned}
$$

where

$$
U_{n}\left(c_{t}^{o}, n_{t}\right)=-\left(1-\theta n_{t}^{\phi}\right)^{-\sigma}\left(\frac{c_{t}^{o}}{c_{t-1}^{\chi}}\right)^{1-\sigma} \theta \phi n_{t}^{\phi-1}
$$

$U_{n}\left(c_{t}^{r t}, n_{t}\right)$ is defined analogously, while $\pi_{W, t}$ is real wage inflation, that is $\frac{w_{t}}{w_{t-1}}$. 


\subsection{Firms}

The goods market is characterized by monopolistic competition of the Dixit-Stiglitz type. Firms produce differentiated goods $z$ in the interval $(0,1)$, which are then aggregated $^{5}$ in the consumption bundle consumed by households.

Firm producing good $\mathrm{z}$ maximises profits under a Cobb-Douglas production function and a downward sloping demand function. It also invests, accumulates capital and is subject to a capital adjustment cost and to a quadratic price adjustment cost. The government levies corporate taxes whose tax base is firm profit before investment. Hence, reinvested earnings are not tax deductible. ${ }^{6}$ The problem is the following:

$$
\begin{gathered}
\max E_{0} \Sigma_{t=0}^{\infty} \beta^{t} \lambda_{t}^{o}\left[d_{Z, t}\right] \\
s t \quad d_{Z, t} \leq\left(1-\tau_{K, t}\right)\left(\frac{P_{Z, t}}{P_{t}} y_{Z, t}-w_{t} n_{Z, t}^{d}-\frac{K}{2}\left(\frac{P_{Z, t}}{P_{Z, t-1}}-1\right)^{2} y_{Z, t}\right)-i n v_{Z, t} \\
y_{Z, t} \leq A_{t}\left(n_{Z, t}^{d}\right)^{\alpha} K_{Z, t-1}^{1-\alpha}-f c \\
y_{Z, t}=\left(\frac{P_{Z, t}}{P_{t}}\right)^{-\mu} y_{t} \\
k_{Z, t} \leq(1-\delta) k_{Z, t-1}+\omega\left(i n v_{Z, t}, k_{Z, t-1}\right) k_{Z, t-1}
\end{gathered}
$$

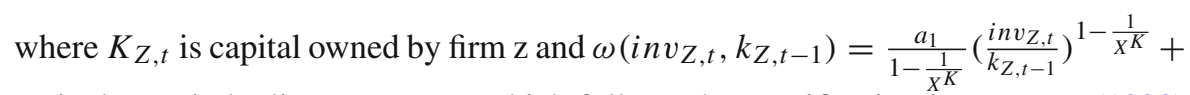
$a_{2}$ is the capital adjustment cost, which follows the specification in Jermann (1998) and Uhlig (2007). In this formulation, $X^{K}$ represents the elasticity of the investment to capital ratio with respect to Tobin's Q: the capital adjustment cost is a decreasing function of $X^{K}$.

Notice that the discount factor used by firms is obtained from the marginal utilities of ricardian households since firms are owned by them. After aggregating among firms and noticing that all of them fix the same price, the first order conditions for the representative firm are:

$$
\begin{gathered}
w_{t}\left(1-\tau_{K, t}\right)=m c_{t} A_{t} \alpha n_{t}^{\alpha-1} k_{t-1}^{1-\alpha} \\
q_{t}=\frac{1}{\left(a_{1}\left(\frac{i n v_{t}}{k_{t-1}}\right)^{-\frac{1}{X^{K}}}\right)}
\end{gathered}
$$

\footnotetext{
5 Such aggregation can be done either by a final good firm or directly by households. Using one device or the other does not affect the properties of the model.

6 Allowing for investment tax deductions would make sure that the capital tax does not distort the consumption-investment decision. We assume the absence of invetsment allowances to keep consistency with the literature.
} 


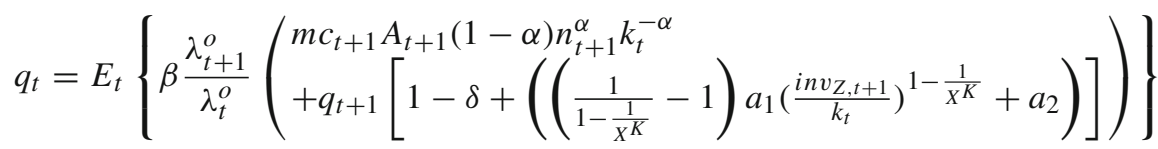

$$
\begin{aligned}
& m c_{t}=\left(1-\tau_{k, t}\right)\left[\frac{\mu-1}{\mu}+\frac{K}{\mu_{t}}\left(\pi_{t}-1\right) \pi_{t}-\beta E_{t}\left[\frac{\lambda_{t+1}^{o}}{\lambda_{t}^{o}} \frac{K}{\mu_{t}}\left(\pi_{t+1}-1\right) \pi_{t+1} \frac{y_{t+1}}{y_{t}}\right]\right] \\
& y_{t}=A_{t} n_{t}^{\alpha} k_{t-1}^{1-\alpha}-f c \\
& k_{t}=(1-\delta) k_{t-1}+\omega\left(\text { inv }_{t}, k_{t-1}\right) k_{t-1} \\
& d_{t}=\left(1-\tau_{k, t}\right)\left(y_{t}-w_{t} n_{t}-\frac{K}{2}\left(\pi_{t}-1\right)^{2} y_{t}\right)-i n v_{t}
\end{aligned}
$$

where $m c_{t}$ are real marginal costs, $q_{t}$ is Tobin's $\mathrm{Q}$ and $\pi_{t}$ is the price index inflation. $A_{t}$ is the technology variable and follows a $\mathrm{AR}(1)$ process of the form $\log A_{t}=$ $\rho_{A} \log A_{t-1}+\varepsilon_{A, t}$, with $\varepsilon_{A, t}$ distributed as a i.i.d. $n\left(0, \sigma_{A}^{2}\right)$.

\subsection{Government Budget Constraint}

The government budget constraint is as follows:

$$
b_{t}+\tau_{c, t} c_{t}+\tau_{k, t}\left(y_{t}-w_{t} n_{t}-\frac{K}{2}\left(\pi_{t}-1\right)^{2} y_{t}\right)+\tau_{n, t} w_{t} n_{t}=g_{t}+\frac{b_{t-1} i_{t-1}}{\pi_{t}}
$$

where $g_{t}$ is real public consumption, which is exogenously given, and $b_{t}$ is the real public debt outstanding.

\subsection{Ramsey Planner}

Define the vector of variables $x_{t}=\left[\lambda_{t}^{o} c_{t}^{o} b_{t} c_{t}^{r t} \lambda_{t}^{r t} c_{t} \lambda_{t} n_{t} w_{t} q_{t} i n v_{t} m c_{t} y_{t} k_{t} d_{t} \pi_{t}\right]$. The competitive equilibrium of the model economy is defined as the sequence of private sector decisions $\{x\}_{t=0}^{\infty}$ that satisfy Eqs. (3)-(19) and the relevant transversality conditions, taking as given the policy sequences $\left\{\tau_{k}\right\}_{t=0}^{\infty},\left\{\tau_{n}\right\}_{t=0}^{\infty},\left\{\tau_{c}\right\}_{t=0}^{\infty}$ and $\{i\}_{t=0}^{\infty}$ and the exogenous processes $\{A\}_{t=0}^{\infty}$ and $\{g\}_{t=0}^{\infty}$. There will be a continuum of competitive equilibria indexed by the sequences $\left\{\tau_{k}\right\}_{t=0}^{\infty},\left\{\tau_{n}\right\}_{t=0}^{\infty},\left\{\tau_{c}\right\}_{t=0}^{\infty}$ and $\{i\}_{t=0}^{\infty}$. The Ramsey planner solution is a competitive equilibrium in which the sequences $\left\{\tau_{k}\right\}_{t=0}^{\infty}$, $\left\{\tau_{n}\right\}_{t=0}^{\infty},\left\{\tau_{c}\right\}_{t=0}^{\infty}$ and $\{i\}_{t=0}^{\infty}$ are chosen in order to maximise the following social welfare function:

$$
V=E_{0} \sum_{t=0}^{\infty} \beta^{t}\left[(1-\psi) U\left(c_{t}^{o}, n_{t}\right)+\psi U\left(c_{t}^{r t}, n_{t}\right)\right]
$$

As already mentioned, I look at the asymptotic behaviour of the economy under Ramsey optimal policy, as is standard in the literature (see Schmitt-Grohé and Uribe 
2004). I solve for the planner's first order conditions using Matlab and use my version of the OLS approach proposed in Schmitt-Grohe and Uribe (2011) to solve for the steady state. The dynamics around the steady state is computed using Dynare.

\section{Calibration}

The time unit is meant to be a quarter. The calibration of the deep parameters of the model is consistent with the literature. I calibrate the discount factor $\beta$ to $1 / 1.01$, the steady state mark-ups to 0.2 , by setting $\mu=v=6$, quarterly capital depreciation $\delta$ to 0.025 and the Rotemberg parameters for price and wage stickiness to 76 , such that if a Calvo model was used instead, ${ }^{7}$ nominal prices would be readjusted every 4.5 quarters. Such frequencies are not far from estimates in the literature, see Colciago (2011) and Smets and Wouters (2007). I set the share of labour in the production function $\alpha$ to $70 \%$, as in Schmitt-Grohé and Uribe (2006). I calibrate $\theta=0.5307$ such that under an efficient steady state, hours worked would be equal to one. ${ }^{8} \phi$ is set such that the Frisch elasticity is about $1.3,{ }^{9}$ which is in line with macro estimates (see for instance Fiorito and Zanella 2012). The calibration of $X^{K}$ follows De Graeve et al. (2010) who set it equal to 0.5. As in Christiano et al. (2005), fixed cost $f c$ represents the $20 \%$ of steady state output, such that economic profits in steady state are zero. The share of RT consumers is $40 \%$, within the range estimated in the literature reported in the introduction. I consider two different initial levels for public debt: in the first I set it to zero and in the second I set it equal to the $44 \%$ of yearly GDP as in SchmittGrohé and Uribe (2004). The share of steady state government consumption over GDP is calibrated to 0.19 , consistently with US data. The standard deviation of the productivity shock $\sigma_{A}$ is set to 0.01 and its persistence $\rho_{A}$ to 0.95 as in De Paoli et al. (2010).

As mentioned in the introduction, I consider different values for the coefficient $\sigma$, which governs the curvature of the utility function with respect to consumption and the degree of non separability between hours worked and consumption. This coefficient is very important as the more concave is the utility function the stronger is the planner's desire to redistribute income. In particular, I consider two calibrations of $\sigma$. In the baseline model I set it to one: this corresponds to the log-utility case with utility function separability. When analysing the implications of the availability of fiscal tools for the optimal redistributive policy along the business cycle I consider also a value of $\sigma$ equal to 5. This value is often used in the macro-finance literature (see De Paoli et al. 2010).

\footnotetext{
7 Keen and Wang (2007) show how to convert a Calvo parameter into a Rotemberg parameter.

8 We get this result by calculating the steady state of a social planner problem and finding the value of $\theta$ that guarantees $N=1$.

9 Notice that under the functional form considered in the paper the Frisch elasticity is $\frac{1}{\phi\left(1+\frac{\theta N_{s S}^{\phi}}{1-\theta N_{s S}^{\phi}}\right)-1}$
}

The Frisch elasticity depends on steady state hours worked. For this reason, changing the parametrization of the model affects the Frisch elasticity even if $\phi$ is kept constant. Nevertheless, the Frisch elasticity never changes drastically in the latter case. 


\section{Ramsey Steady State}

Table 2 reports the values of some variables of interest in the Ramsey steady state as a percentage of the corresponding first best values, under LAMP and under the representative agent model. The first best can be obtained by solving the social planner problem, which consists in maximising over an infinite horizon the social welfare function under the production function, the aggregate resource constraint and the capital accumulation equation. In practice, the first best can be obtained assuming that the economy is centrally planned by a benevolent dictator who decides how many hours each agent has to work and how much each agent can consume. It can be easily shown that the first best requires that all agents work the same number of hours and consume the same amount of the consumption good. The Ramsey planner on the contrary has to respect all the competitive equilibrium conditions of the economy, and can affect allocations only through her choices concerning taxes and the nominal interest rate. The optimum under the Ramsey problem is a second best, in that it is not possible to eliminate all the distortions which are present in the economy.

The steady state of the competitive economy presents several distortions that it would be efficient to eliminate. First of all, the economy features monopolistic competition in the goods and labor markets, which generates inefficient rents and reduces the amount of labor employed and of goods produced with respect to the first best. Price and nominal wage adjustment costs imply that price and wage changes destroy real resources. Limited asset market participation generates wealth and consumption inequality which the planner dislikes, due to utility function concavity. Lastly, the Ramsey planner is obliged to finance an exogenous stream of public consumption which is pure waste, as it enters neither the utility function of agents nor the production function of firms, and has to do it by levying distortionary taxation, as a technology to collect lump-sum taxes is not available by assumption. The presence of such distortions is evident when observing Table 2. Worked hours, capital levels and output are all less than $80 \%$ than their corresponding values under the first best, in all the models under consideration. Aggregate consumption is even less than $60 \%$. Furthermore, in

Table 2 Deterministic steady state - all values apart from inflation and tax rates are as a percentage of the corresponding first best level

"_-" refers to variables that are not present

\begin{tabular}{llllll}
\hline & \multicolumn{2}{l}{ Ramsey Planner $\psi=0$} & & \multicolumn{2}{l}{ Ramsey Planner $\psi=0.4$} \\
\cline { 2 - 3 } \cline { 5 - 6 } & $\frac{b}{4 y}=0$ & $\frac{b}{4 y}=0.44$ & & $\frac{b}{4 y}=0$ & $\frac{b}{4 y}=0.44$ \\
\hline$n$ & 0.77 & 0.76 & & 0.79 & 0.78 \\
$k$ & 0.6848 & 0.6737 & & 0.709 & 0.6894 \\
$y$ & 0.7454 & 0.7359 & & 0.7693 & 0.7502 \\
$c$ & 0.5790 & 0.5661 & 0.5918 & 0.5790 \\
$c^{o}$ & - & - & 0.6433 & 0.6497 \\
$c^{r t}$ & - & - & 0.5082 & 0.4825 \\
$\pi$ & 0 & 0 & 0 & 0 \\
$\tau_{k}$ & -0.101 & -0.1 & -0.109 & -0.1 \\
$\tau_{n}$ & 0.307 & 0.29 & 0.16 & 0.208 \\
$\tau_{c}$ & 0.01 & 0.06 & 0.19 & 0.16 \\
\hline
\end{tabular}


the LAMP model, consumption inequality arises, in that ricardian agents consume around $64 \%$ of the amount they would consume in the first best while RT consumers only around $50 \%$. Such results suggest that even if the Ramsey planner sets taxes and the nominal interest rate optimally, the welfare losses with respect to the first best are substantial.

The optimal rate of inflation is zero under all model specifications. As is well known, in fact, in this kind of model the trade off between using inflation to reduce the monopolistic power of firms and setting it to zero to eliminate price adjustment costs is resolved in favor of the latter (see for instance Khan et al. 2003). Such a result is not affected by the introduction of LAMP. The results concerning the optimal steady state tax rates are instead more interesting.

In the representative agent model, the Ramsey planner subsidizes capital by setting the capital income tax rate to around $-10 \%$ and relies on labor taxes and consumption taxes to raise revenues. In particular, the labor tax rate is set to $30.7 \%$ when government debt is zero and to $29 \%$ when government debt is $44 \%$ of GDP. Consumption taxes are set respectively at 1 and $6 \%$. While the optimality of the capital subsidy is an established result in the literature (as shown for instance by Schmitt-Grohé and Uribe 2006), the results concerning labor and consumption taxes are somewhat surprising, as a long stream of literature (see for instance Coleman 2000) has shown that consumption taxes are preferable to labor taxes in representative agent models. In a separate experiment, I verified that consumption taxes are again preferable if I eliminate fixed costs from the model, which suggests that fixed costs rather than the other frictions are responsible for the result.

Introducing LAMP in the model slightly increases, coeteris paribus, hours worked, capital and output. Any dispersion in the marginal utility of consumption of the two agents induces unions to increase the supply of labor for any wage level. In fact, due to the concavity of the utility function, the wealth effect on labor supply depends more on the consumption of the poorest than on the consumption of the wealthiest. The increase in labor supply augments the productivity of capital, stimulates its accumulation and increases output.

The optimal tax scheme is substantially affected by LAMP. While it remains optimal to subsidize capital income (the subsidy is around $10 \%$ ), the Ramsey planner relies more on consumption taxes and less on labor taxes. The labor tax rate is 16 and $20.8 \%$ respectively when public debt is zero and when public debt is $44 \%$ of GDP, while the consumption tax rate is 19 and $16 \%$. Hence, the labor tax rate is substantially smaller than in the representative agent case and the consumption tax rate substantially higher. The reason for this is that consumption taxes allow to tax monopolistic profits indirectly, while the latter cannot be affected through the labor tax. This fact raises the question of why the Ramsey planner does not use capital taxes to reduce profit income. The reason for this is that using capital income taxes to redistribute is very inefficient, as it lowers the long run capital level, with obvious negative effects on labor productivity and real wages. Lower real wages in fact end up reducing RT consumers' income substantially, making such a redistributive scheme self-defeating.

Steady state public debt slightly reduces output and consumption because it requires higher distortionary taxes. However, the basic results are unaffected, at least from a qualitative point of view. 


\section{Ramsey Dynamics}

In this section, I present the optimal dynamics of the economy. First I compute optimal second moments, then I discuss impulse response functions to a productivity shock.

\subsection{Moments}

Since my model solution features a unit root, theoretical unconditional moments do not exist and variables may wander far away from the steady state in the long run. As a consequence, local approximations behave very poorly the longer the simulation lenght. On the other hand, my model contains too many state variables for global solution methods to be employed. I adopt the procedure described in Schmitt-Grohé and Uribe (2004): I compute $\mathbf{J}$ simulations of lenght T periods and take the arithmetic average of the moments. Schmitt-Grohé and Uribe (2004) show in a simpler model that a first order approximation is good as long as the simulation period is not very long and set $\mathrm{J}=500$ and $\mathrm{T}=100$. I adopt the same values (Table 3 ).

Optimal inflation volatility is almost equal to zero under LAMP as well as under the representative agent model. This result is standard: optimal monetary policy is not influenced by the RT hypothesis. The overall volatility of the economy is higher under LAMP than under the representative agent model. Output for instance has a standard deviation of $4.46 \%$ in the representative agent model and of $5.95 \%$ in the LAMP model, when public debt is zero. This at least partially depends on the different characteristics of fiscal policy under the two models. Under LAMP all tax rates are more volatile $(64.42 \%$ against $42.26 \%$ for the capital tax, $13.74 \%$ against $9.53 \%$ the labor tax and $18.37 \%$ against $13.1 \%$ the consumption tax); moreover the standard

Table 3 Optimal second order moments

\begin{tabular}{|c|c|c|c|c|c|c|c|c|}
\hline & \multicolumn{4}{|l|}{$\psi=0$} & \multicolumn{4}{|c|}{$\psi=0.4$} \\
\hline & \multicolumn{2}{|l|}{$\frac{b}{4 y}=0$} & \multicolumn{2}{|c|}{$\frac{b}{4 y}=0.44$} & \multicolumn{2}{|c|}{$\frac{b}{4 y}=0$} & \multicolumn{2}{|c|}{$\frac{b}{4 y}=0.44$} \\
\hline & Stdev & Autcor & Stdev & Autcor & Stdev & Autcor & Stdev & Autcor \\
\hline$n$ & 0.0109 & 0.1301 & 0.0087 & 0.0734 & 0.02 & 0.2456 & 0.0215 & 0.2134 \\
\hline$i n v$ & 0.0098 & 0.5648 & 0.0065 & 0.8621 & 0.0134 & 0.5121 & 0.0095 & 0.7748 \\
\hline$y$ & 0.0446 & 0.5396 & 0.0396 & 0.5344 & 0.0595 & 0.4721 & 0.0602 & 0.4285 \\
\hline$c$ & 0.0349 & 0.5338 & 0.0356 & 0.4093 & 0.0461 & 0.4621 & 0.1357 & 0.3518 \\
\hline$c_{O}$ & - & - & - & - & 0.0588 & 1 & 0.0687 & 0.3775 \\
\hline$c_{R T}$ & - & - & - & - & 0.0293 & 0.5122 & 0.029 & 0.3262 \\
\hline$i$ & 0.016 & 0.1051 & 0.0202 & -0.1523 & 0.0212 & 0.3264 & 0.0148 & -0.2745 \\
\hline$\pi$ & 0 & 0.9096 & 0 & 0.9256 & 0 & 0.9361 & 0 & 0.8712 \\
\hline$\tau_{k}$ & 0.4226 & 0.2123 & 0.4741 & 0.1010 & 0.6442 & 0.2385 & 0.7026 & 0.1366 \\
\hline$\tau_{n}$ & 0.0953 & 0.8766 & 0.1101 & 0.3878 & 0.1374 & 0.9475 & 0.0987 & 0.9482 \\
\hline$\tau_{c}$ & 0.121 & 0.9337 & 0.0984 & 0.888 & 0.1837 & 0.9432 & 0.1357 & 0.9213 \\
\hline$b$ & 1.0684 & 0.9822 & 1.0820 & 0.9793 & 1.6101 & 0.9737 & 1.5159 & 0.9668 \\
\hline
\end{tabular}



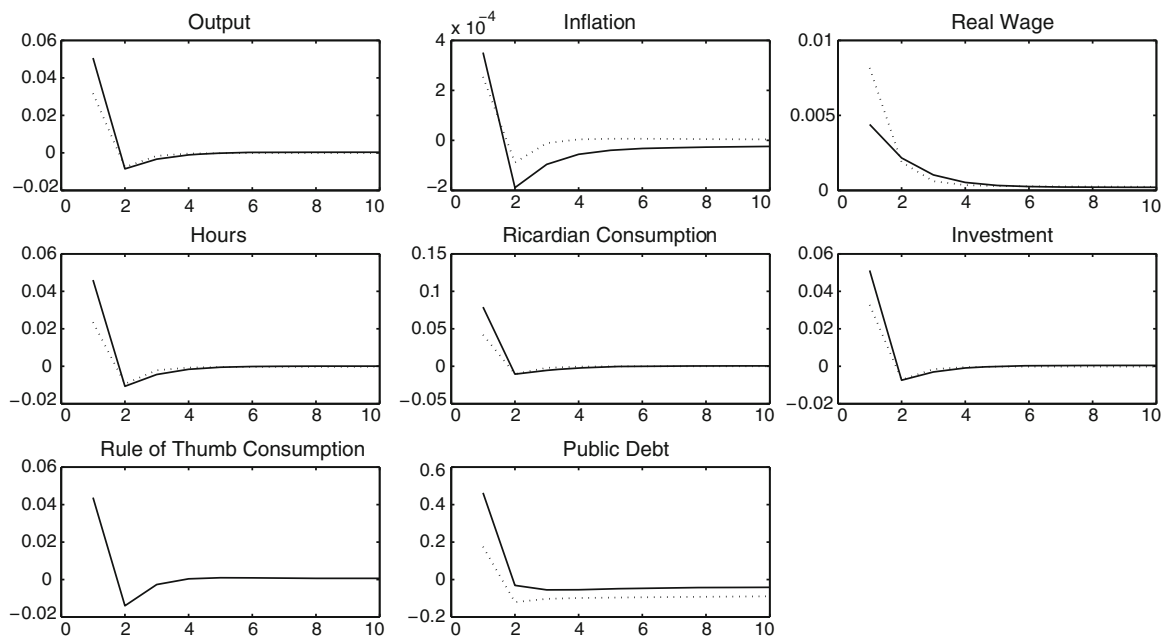

Fig. 1 Impulse responses to a one standard deviation productivity shock. Full line LAMP model. Dotted line representative agent model. All responses, apart from public debt and inflation are in percentage points deviations from the steady state. Public debt and inflation are reported as deviation from the steady state in levels

deviation of the consumption of Ricardian agents $(5.88 \%)$ is much higher than that of RT consumers $(2.93 \%)$ and than that of the representative agent $(3.49 \%)$ in the model with $\psi=0$. Such results suggest that the Ramsey planner is willing to accept a higher volatility of the overall economy in order to make RT consumers better off. The analysis delivered in the next sections helps to understand this point.

\subsection{Impulse Responses}

The impulse response functions to a positive productivity shock under LAMP and under the representative agent model are in Figs. 1 and 2. To sharpen the analysis and enhance intuition, I assume that public debt is zero in steady state and that the productivity shock is not autocorrelated.

The optimal responses of the Ramsey planner under LAMP and under the representative agent model share some common properties. Inflation is almost completely stabilised (it increases by less than $4 \times 10^{-4}$ ), nominal rates are lowered aggressively and the subsidy on capital is highly volatile. ${ }^{10}$ These results are well known. It is in fact optimal to stabilise firm mark-ups by using monetary policy and to tax (or sub-

\footnotetext{
10 In particular, the nominal interest rate falls by more than $10 \%$ under LAMP and by slightly less than $10 \%$ under the representative agent model, while the capital subsidy increases to over $100 \%$. As I explain later, also labor and consumption tax rates respond substantially at impact. The optimality of extremely volatile tax rates has already been explored in the literature (see the various contributions of Schmitt-Grohe and Uribe reported in the references). Of course, such extreme policy proposals would be impossible to implement in practice. However, even if they cannot be taken at face value from a quantitative point of view, results in this section are nonetheless suggestive qualitatively.
} 

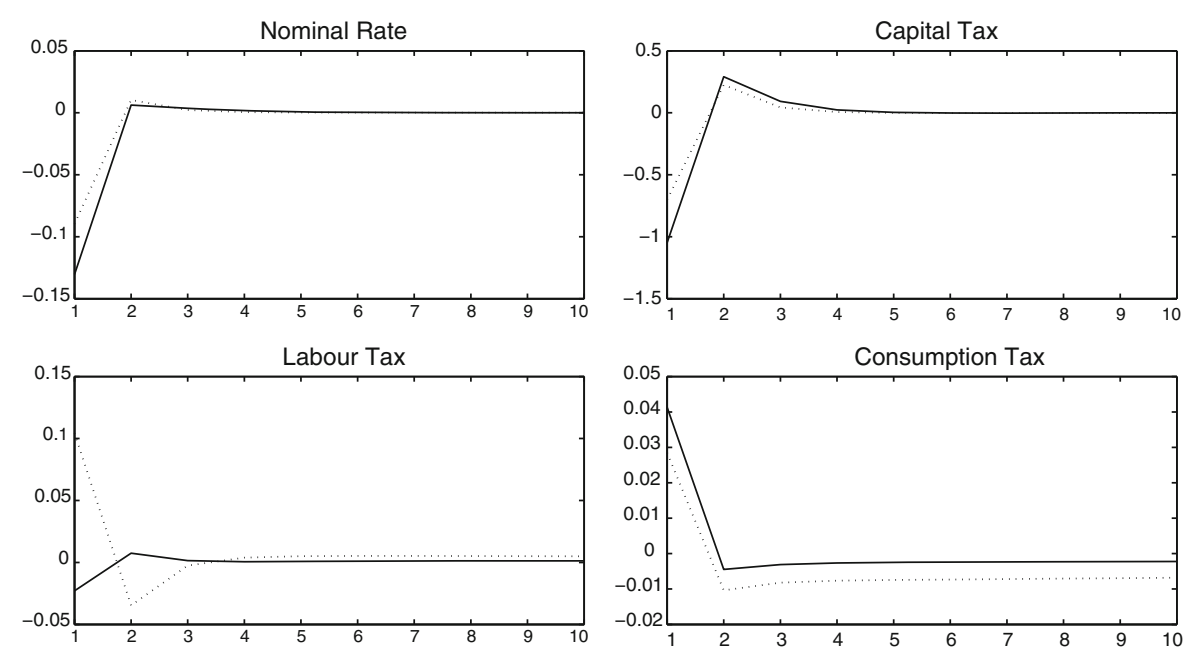

Fig. 2 Impulse responses to a one standard deviation productivity shock. Full line LAMP model. Dotted line representative agent model. All responses are in deviations from the steady state in levels

sidise) more strongly production factors which are in fixed supply or predetermined, as is capital in this model.

Under the representative agent model, both consumption taxes and labor taxes are strongly increased at impact, the former rising by around $3 \%$ and the latter by around $10 \%$. This behaviour can be rationalized if wage stickiness is taken into consideration. Under the first best, hours worked would fall slightly as the wealth effect overcomes the substitution effect. ${ }^{11}$ In a competitive economy with nominal rigidities, managing the nominal interest rate allows to stabilise firms' mark up but not necessarily the mark up of wages over the marginal rate of substitution. In particular, once the Ramsey planner stabilises inflation by stimulating aggregate demand through interest rate cuts, she tends to drive hours worked above the efficient level. Wage stickiness, in fact, reduces the leftward shift of the wage setting schedule, which implies that real wages grow less and hours more than under the first best. As a consequence, the wage mark up over the marginal rate of substitution decreases. The scope of the higher consumption and labor taxes is to increase the tax wedge on labor, disincentivating exccessive labor supply.

Under LAMP the consumption tax increases somewhat more, the labor tax falls and the nominal rate goes down more strongly. Public debt is increased by more. Output, consumption, investment and hours respond more strongly than under the representative agent model. The Ramsey planner wants to offset the large fluctations in the consumption ratios of the two agents provoked by productivity shocks. In fact, the productivity shock tends to increase inequality through two channels. First, due to price stickiness, prices do not fall enough to compensate the reduced production costs. As a consequence, absent an expansionary monetary policy, mark-ups would increase,

11 Agents' income goes up by more of the real wage, because of increased capital income. 
thereby raising monopolistic profits, which only accrue to ricardian consumers. A substantial reduction of the nominal interest rate can stabilize prices, and eliminate this effect. Second, the productivity shock increases the marginal productivity of capital and hence capital income, which also only accrues to ricardian agents and increases inequality. The latter effect cannot be cured by monetary policy. In order to tackle this issue, the Ramsey planner adopts the following strategy. She borrows funds from ricardian agents, by increasing public debt more than what she would do under the representative agent model, and uses such funds to reduce the labor tax, which increases the disposable income of RT consumers. Furthermore, she increases the consumption tax, whose burden falls more on ricardian agents, as explained in Sect. 4.

\subsection{Optimal Fiscal Policy as a Device to Smooth Income Distribution Fluctuations}

While steady state analysis allows to understand how taxation is implemented to redistribute, at least partially, income and reduce inequality; the analysis of the dynamics of the model economy allows to gather intuition on how the Ramsey planner can use fiscal policy to reduce fluctuations in income distribution. When shocks are symmetric and the Ramsey planner response to them is also constrained to be symmetric, ${ }^{12}$ in fact, the best achievable result is that of a complete elimination of all idyosincratic risks. That is exactly what agents would do if both ricardians and RT consumers were allowed to invest in contingent securities. In my case, the productivity shock is symmetric by assumption. Moreover, I solve the model using first order perturbation methods which eliminate any possibility of an asymmetric response of the Ramsey planner to shocks. Employing an higher order perturbation approach would in principle allow to consider non symmetric responses to shocks. However, for perturbation methods to be accurate, shocks must be small and in this case the non-linearities which are present in the model are unlikely to produce significant asymmetric responses on the part of the planner. My objective is to check if using fiscal tools can enhance substantially the ability of the Ramsey planner to reduce fluctuations in income distribution, which are more difficult to control using only monetary instruments.

In order to analyse this question, I first define the ratio between the marginal utility of consumption of the two agents: $R=\left(\frac{c_{t}^{o}}{c_{t}^{r t}}\right)^{-\sigma} . R$ is always equal to one under the first best and its standard deviation is zero. Then I compare the impulse response function of $R$ in the Ramsey model with fiscal instruments to the impulse response function of $R$ under a Ramsey model in which the planner can only move the nominal interest rate and under a model in which monetary policy is conducted through a simple Taylor rule with coefficient 1.5 on inflation. To make the results comparable, I assume that under all three models steady state public expenditure is zero. A positive level of steady state public consumption would entail the use either of non distortionary taxation or of simple fiscal rules in the models where the planner cannot optimize with respect to fiscal instruments, which would make the comparison of the results of the three

12 As we are going to make clear later, this is the case here. 


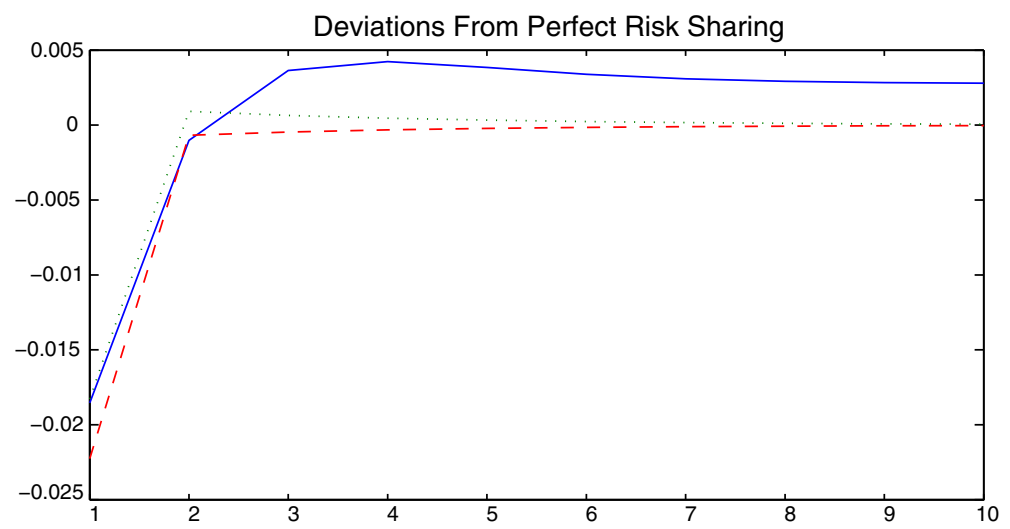

Fig. 3 Impulse response of $\mathrm{R}$ to a one standard deviation productivity shock with $\sigma=1$. Blue line Ramsey with fiscal instruments. Black line Ramsey without fiscal instruments. Red line Taylor rule. The response is in percentage points deviation from the steady state (colour figure online)

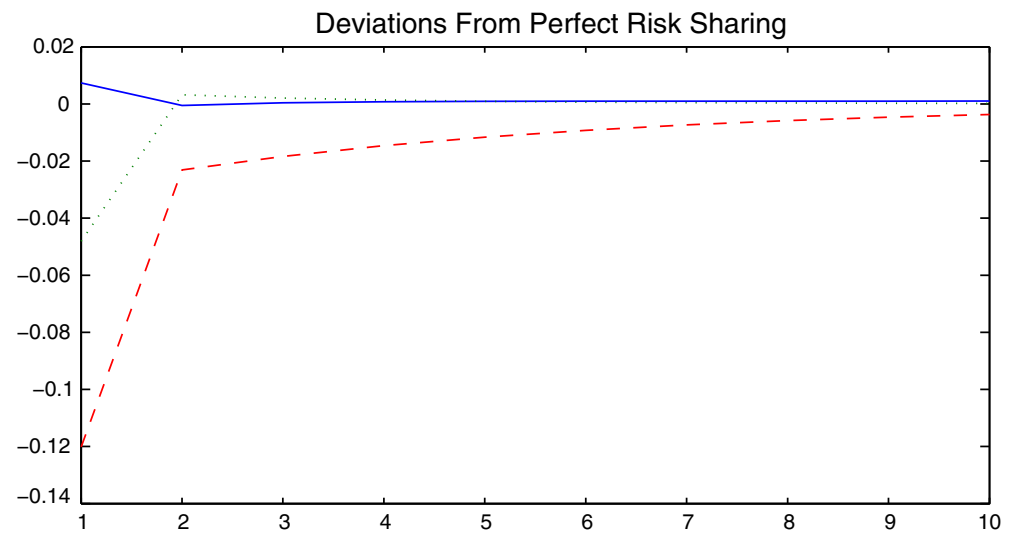

Fig. 4 Impulse response of $\mathrm{R}$ to a one standard deviation productivity shock with $\sigma=5$. Blue line Ramsey with fiscal instruments. Black line Ramsey without fiscal instruments. Red line Taylor rule. The response is in percentage points deviation from the steady state (colour figure online)

models less intuitive. For the sake of illustration, I consider two values for $\sigma$ : in Fig. 3 $\sigma$ equals one and in Fig. 4 it equals five.

Differences in the responses of $R$ between the case in which the planner can use fiscal instruments and the case in which it can not, critically depends on the concavity of the utility function. When $\sigma=1$, the response of fiscal policy, even if very strong as underlined in the previous section, does not seem to entail important differences in the fluctuations of the ratio of agents' marginal utilities. Indeed, a relatively low curvature of the utility function implies that fluctuations in consumption and in the distribution of income over time are not very costly. In this case, indeed, fiscal instruments do not reduce very much the fall of $\mathrm{R}$ following a productivity shock. With $\sigma=5$ instead fiscal policy is used to stabilise income distribution. Indeed, there is a slight increase in $\mathrm{R}$ following the shock. With a relatively high curvature of the utility function, 
fluctuations in the distribution of income are very costly and the role of fiscal policy becomes more important. ${ }^{13}$

As already mentioned, monetary policy is less effective than fiscal policy in reducing fluctuations in income distribution because it has two effects that work in opposite directions. On the one hand monetary policy can close the marginal cost gap and eliminate fluctuations in mark ups and extra-profits. This tends to reduce the surge of inequality produced by productivity shocks. But closing the marginal cost gap also stimulates the demand for production factors, and while the higher demand for labor increases labor income for both agents, the higher demand for capital only benefits ricardians. This implies that ricardian agents income is pushed up more than that RT consumers and monetary policy can not do anything to reduce the increase in inequality that follows. Here is where fiscal policy plays its role. By borrowing funds from ricardian agents to subsidize labor, the Ramsey planner is able to reduce the gap between the consumption of the two agents. In the case of a negative productivity shock instead, the Ramsey planner taxes labor to lend the revenues to Ricardians, again reducing the fluctuation in relative marginal utility.

\section{Conclusions}

I check if standard results concerning optimal policy in DSGE models are robust to the introduction of agent heterogeneity in the form of limited asset market participation. I analyze the issue in a fully fledged DSGE model with nominal and real rigidities in which the Ramsey planner has access to a wide range of fiscal instruments, besides the nominal interest rate. In particular I assume that the planner can use taxes on labor, consumption and capital.

I find that monetary policy maintains the role of completely stabilizing inflation, but is not very useful in tackling the inefficiencies linked to LAMP. In particular, it is unable to tackle inequality in steady state and has limited traction in reducing swings in income distribution. Fiscal policy can instead play its role both in the steady state, reducing inefficiencies due to monopolistic competition and inequality, and along the business cycle, attenuating the fluctuations in income distribution. These objectives are not reached by using capital taxation. Indeed I confirm the standard results of optimal taxation in representative agent models that capital should not be taxed and it should be subsidized in the presence of monopolistic competition. Taxing capital to redistribute income is particularly inefficient, because it depresses the long-run capital level reducing labor productivity and wages, with negative consequences also for RT consumers. Redistribution is better complied with by a stronger use of consumption taxation in place of labor taxation.

Along the business cycle, LAMP implies that it is optimal to let government deficits fluctuate more heavily and to use public debt to attenuate the effect of the productivity shock on income distribution. In particular, following a positive productivity shock it is

\footnotetext{
13 Notice that when $\sigma=5$, the Ramsey planner adopts a more redistributive policy stance also in the steady state. With $\sigma=1$ and $g=0$, in fact, she sets $\tau_{n}=0.35$ and $\tau_{k}=-0.1$ and $\tau_{c}=-0.28$. With $\sigma=5$ instead the optimal tax scheme is $\tau_{n}=0.05$ and $\tau_{k}=0$ and $\tau_{c}=-0.04$. Along the business cycle, the response of fiscal variables is similar but stronger for relatively high values of $\sigma$.
} 
optimal to cut labor taxes and let public debt increase strongly. Such a policy reaction is totally different from the optimal response under the representative agent model. In that model indeed the labor and the consumption tax rates are strongly increased. The difference in the behaviour of the Ramsey planner is due to the fact that under LAMP the planner wants to reduce fluctuations in income distribution as much as possible. Productivity shocks tend to raise income inequality because they trigger positive responses of profits and capital income. Financing a labor tax cut through an increase in public debt amounts to subsidising RT consumers' income borrowing funds from ricardian agents. The Ramsey planner uses public debt to balance the effect of the shock on income distribution.

My results suggest that fiscal activisms can be important to reduce steady state inequality and to limit the negative effects of shocks on agents' welfare. Such results can be obtained even in the absence of targeted transfers, by intelligently manipulating consumption and labor tax rates and by letting budget deficits react more strongly to shocks.

\section{References}

Alvaredo F, Atkinson AB, Piketty T, Saez E (2013) The top 1 percent in international and historical perspective. J Econ Perspect Am Econ Assoc 27(3):3-20 (Summer)

Ascari G, Colciago A, Rossi L (2011) Limited asset market participation: does it really matter for monetary policy? Research Discussion Papers 15/2011, Bank of Finland

Blanchard O, Galí J (2007) Real Wage Rigidities and the New Keynesian Model. J Money Credit Bank. Blackwell Publishing 39(s1):35-65, 02

Chamley CP (1981) The welfare cost of capital income taxation in a growing economy. J Polit Econ 89:468-496

Chamley CP (1986) Optimal taxation of capital income in general equilibrium with infinite lives. Econometrica 54:607-622

Chari VV, Christiano LJ, Kehoe PJ (1994) Optimal fiscal policy in a business cycle model. J Polit Econ 102:617-652

Christiano LJ, Eichenbaum M, Evans CL (2005) Nominal rigidities and the dynamic effects of a shock to monetary policy. J Polit Econ. University of Chicago Press. 113(1):1-45 (February)

Colciago A (2011) Rule-of-Thumb Consumers Meet Sticky Wages. J Money Credit Bank. Blackwell Publishing 43:325-353, 03

Coleman II WJ (2000) Welfare and optimum dynamic taxation of consumption and income. J Public Econ Elsevier 76(1):1-39

De Graeve F, Dossche M, Emiris M, Sneessens H, Wouters R (2010) Risk premiums and macroeconomic dynamics in a heterogeneous agent model. J Econ Dyn Control. Elsevier 34(9):1680-1699 (September)

De Paoli B, Scott A, Weeken O (2010) Asset pricing implications of a New Keynesian model. J Econ Dyn Control. Elsevier 34(10):2056-2073 (October)

Fiorito R, Zanella G (2012) The anatomy of the aggregate labor supply elasticity. Rev Econ Dyn Elsevier Soc Econ Dynam 15(2):171-187 (April)

Furlanetto F (2009) Fiscal Shocks and Real Rigidities. B.E. J Macroecon De Gruyter 9(1):1-33 February

Furlanetto F, Seneca M (2012) Rule-of-thumb consumers, productivity, and hours. Scand J Econ Wiley Blackwell 114(2):658-679

Galì J, Lopez-Salido D, Valles J (2004) Rule-of-Thumb consumersand the design of interest rate rules. J Money Credit Bank 36:739-764

Jermann J (1998) Asset pricing in production economies. J Monet Econ Elsevier 41(2):257-275 (April)

Judd KL (1985) Redistributive taxation in a simple perfect foresight model. J Publ Econ Elsevier 28(1):59_ 83 (October)

Keen B, Wang Y (2007) What is a realistic value for price adjustment costs in New Keynesian models?. Appl Econ Lett 14(11):789-793 
Khan A, King RG, Wolman AL (2003) Optimal monetary policy. Rev Econ Studies Oxford Univ Press 70(4):825-860

Mankiw G (2000) The Savers-Spenders theory of fiscal policy. Am Econ Rev 90(2):120-125

Mehra R, Prescott EC (1985) The equity premium: a puzzle. J Monet Econ Elsevier 15(2):145-161 (March)

Motta G, Tirelli P (2012) Optimal simple monetary and fiscal rules under limited asset market participation. J Money Credit Bank 44(7):1351-1374 (October)

Rachedi O (2016) Portfolio rebalancing and asset pricing with heterogenous inattention. manuscript . http:// sites.google.com/site/omirachedi/research-1

Schmitt-Grohe S, Uribe M (2007) Optimal simple and implementable monetary and fiscal rules. J Monet Econ Elsevier 54(6):1702-1725 (September)

Schmitt-Grohé S, Uribe M (2004) Optimal fiscal and monetary policy under sticky prices. J Econ Theory 114:198-230

Schmitt-Grohé S, Uribe M (2011) An OLS approach to computing Ramsey equilibria in medium-scale macroeconomic models. Econ Lett 115(1):128-129

Schmitt-Grohé S, UribeM (2006) Optimal fiscal and monetary policy in a medium-scale macroeconomic model. In: Gertler M, Rogoff K (eds) NBER, Macroeconomics Annual 2005, Cambridge, MIT Press, pp 383-425

Smets F, Wouters R (2007) Shocks and frictions in US business cycles: a Bayesian DSGE approach. Am Econ Rev Am Econ Assoc 97(3):586-606

Sun B (2011) Limited market participation and asset prices in the presence of earnings management. International Finance Discussion Papers 1019, Board of Governors of the Federal Reserve System (U.S.)

Uhlig H (2007) Explaining asset prices with external habits and wage rigidities in a DSGE model. Am Econ Rev Am Econ Assoc 97(2):239-243

Vissing-Jørgensen A (2002) Limited asset market participation and the elasticity of intertemporal substitution. J Polit Econ 110:825-853 